\title{
Iniciação à investigação qualitativa: Perceção e apreciação de alunos de Psicologia
}

\begin{abstract}
Ana Pereira Antunes ${ }^{1}$ e Sara Barros Araújo²
1 Departamento de Psicologia, Universidade da Madeira, \& Centro de Investigação em Estudos da Criança (CIEC), Universidade do Minho, Portugal | aantunes@uma.pt | https://orcid.org/0000-0002-3336-7867

${ }^{2}$ Escola Superior de Educação \& Centro de Investigação e Inovação em Educação (inED), Instituto Politécnico do Porto, Portugal | saraujo@ese.ipp.pt | https://orcid.org/0000-00029866-0060

Resumo: Dado o interesse crescente e a pertinência da investigação qualitativa na área da Psicologia, importa promover oportunidades de formação aos alunos nesta modalidade de pesquisa científica. A investigação qualitativa revela-se um fator importante na promoção da justiça social, sendo que os psicólogos da Educação parecem recetivos a esta forma de pesquisa. O principal objetivo deste trabalho é conhecer como um grupo de estudantes perceciona a investigação qualitativa e uma unidade curricular de métodos de investigação, centrada na metodologia qualitativa, após a frequência da mesma. O estudo é qualitativo de natureza exploratória. $O$ grupo de participantes era constituído por 11 alunos (10 mulheres e um homem), inscritos num curso de 2.ํ ciclo, em Psicologia da Educação, numa Universidade Pública Portuguesa, no ano letivo 2019/2020, assegurando-se a participação informada e voluntária. A recolha de dados foi efetuada através da produção de narrativas individuais, com tópicos orientadores para a sua redação. Os textos foram alvo de análise de conteúdo, realizada por dois codificadores, seguindo uma lógica dedutiva e indutiva. Os dados obtidos revelam conhecimento dos alunos sobre a investigação qualitativa congregado nas categorias: Paradigmas/Visão do Mundo, Propósito da Investigação, Dimensão do Fenómeno e Pressupostos Ontológico, Metodológico, Epistemológico e Axiológico. No que se refere à unidade curricular destacam-se perceções associadas às categorias: Aspetos motivacionais, Processo Ensino-aprendizagem e Transferência da Aprendizagem. A frequência da unidade curricular parece ter contribuído para o aprofundar do conhecimento dos alunos sobre investigação qualitativa, desmistificando crenças, experimentando, e valorizando esta nova abordagem investigativa, sugerindo a sua lecionação mais cedo no percurso formativo, durante a licenciatura.
\end{abstract}

Palavras-chave: Pesquisa Qualitativa; Aprendizagem; Psicologia da Educação.

Introduction to Qualitative Research: Perception and Assessment of Psychology Students

Abstract: Given the growing interest and the relevance of qualitative research in the field of Psychology, it is important to promote training opportunities for students in this modality of scientific research. Qualitative research proves to be an important factor in promoting social justice. Educational psychologists seem receptive to this research approach. The main objective of this work is to know how a group of students perceives qualitative research and a curricular unit of research methods, centered on qualitative methodology, after its completion. The study has a qualitative and exploratory nature. Participants were a group of 11 students (10 women and one man), enrolled in a 2nd cycle course, in Educational Psychology, at a Portuguese Public University, in the academic year 2019/2020. Informed consent and voluntary participation were ensured. Data collection was carried out through the production of individual narratives, following guiding topics. The texts were subjected to content analysis, carried out by two coders, following a deductive and an inductive logic. The data obtained reveal students' knowledge about the qualitative research organized in the categories: Paradigms/Worldview, Purpose of the Research, Dimension of the Phenomenon and Ontological, Methodological, Epistemological and Axiological Assumptions. Related to the course unit, perceptions associated with the categories Motivational Aspects, Teachinglearning Process and Learning Transfer were highlighted. The attendance of the curricular unit seems to have contributed to the deepening of the students' knowledge about qualitative research, demystifying beliefs, experimenting, and valuing this new investigative approach. They also suggest that qualitative research training should occur earlier in their academic trajectory at undergraduate level.

Keywords: Qualitative Research; Learning; Educational Psychology. 


\section{Introdução}

Ainda que o contributo de investigação de cariz qualitativo se tenha verificado ao longo da história da Psicologia, só nos últimos anos se tem verificado uma disseminação crescente e um reconhecimento científico na área (Gough \& Lyons, 2016).

A opção metodológica preferencial da Psicologia, na linha do positivismo, tem estado associada ao seu percurso histórico de procura de credibilidade científica, ainda que importantes trabalhos qualitativos também tenham sido desenvolvidos (Gibson \& Sullivan, 2012; Murray, 2019).

De facto, metodologias qualitativas são pertinentes nos vetores da Psicologia que se movem por valores de justiça social (Gough \& Lyons, 2016), nomeadamente, na advocacia de direitos e defesa de grupos minoritários, como pode ilustrar o desenvolvimento recente de métodos de pesquisa qualitativa e o combate à injustiça social em países europeus, onde vigoravam regimes políticos mais opressores (Murray, 2019).

Contudo, a reflexão sobre a investigação, e a sua concretização, não deve resumir-se à dicotomia quantitativa-qualitativa, mas conceber a arte da investigação em diferentes epistemologias e metodologias (Gough \& Lyons, 2016). Reflexo desse processo, pode verificar-se, na última edição do Publication Manual of the American Psychological Association (American Psychological Association, 2020), a apresentação, pela primeira vez, de uma secção com orientações ao relato de pesquisa qualitativa e de pesquisa com métodos mistos.

De acordo com Meyer e Schutz (2020), o crescimento do recurso a métodos qualitativos e mistos traduz o trabalho de muitos psicólogos, nomeadamente, psicólogos da Educação, dada a natureza interdisciplinar desta área, pois tem-lhes permitido adotar, de várias outras áreas, estas formas de realizar investigação.

Então, para que a Psicologia Educacional prospere e o trabalho de investigação tenha impacto além do mundo académico, importa que nos tornemos mais "educados metodologicamente" (methodologically educated), independentemente das opções metodológicas pessoais, para assim prestarmos melhor serviço na área, quer sejamos orientadores, investigadores ou revisores (Nolen, 2020). Nesse sentido, são necessárias oportunidades de desenvolvimento profissional, onde os académicos possam experimentar o pluralismo metodológico e apreender a heterogeneidade do campo, sendo que estes momentos contribuem também para a legitimação das metodologias qualitativas como forma de fazer investigação (Meyer \& Schutz, 2020).

Contudo, não só os académicos necessitam ser mais "educados metodologicamente", também os alunos devem ser ensinados sobre a pesquisa qualitativa. De facto, parece que, ao longo da formação académica, os alunos estabelecem mais contacto com a metodologia quantitativa. Com efeito, dada a complexidade da metodologia qualitativa, o seu ensino revela-se complexo e desafiante, não só em termos de técnicas e métodos de ensino, mas também nas opções programáticas de conteúdos nas, e entre, as instituições de formação superior (Gibson \& Sullivan, 2012).

Resultado da preocupação de professores e investigadores com a qualidade da formação, sobretudo quando se deparam com a metodologia qualitativa pela primeira vez, têm surgido alguns trabalhos onde os autores comentam conteúdos e relatam experiências formativas (e.g., Antunes, 2017; Boström, 2019; Danquah, 2017; Wiggins et al., 2016).

O presente trabalho surge também como resultado da preocupação com a formação dos alunos, e na sequência de um trabalho anterior realizado pelas autoras (Antunes \& Araújo, 2020), tendo como objetivo responder às questões de investigação sobre as perceções de um grupo de alunos de mestrado de Psicologia da Educação (PE) sobre a metodologia qualitativa (MQ) e sobre a Unidade Curricular (UC) de Métodos de Investigação II (MI II), com enfoque na MQ, após a frequência da mesma. 


\section{Método}

\subsection{Participantes}

Os participantes deste estudo foram 11 alunos (10 mulheres e um homem) de uma turma de 12 alunos, com idades entre 21 e 28 anos. Os alunos estavam inscritos na UC de MI II, do plano de estudos de um curso de 2.ำ ciclo, em PE, numa Universidade Pública Portuguesa, no ano letivo 2019/2020.

\subsection{Materiais}

Na sequência do trabalho anterior (Antunes \& Araújo, 2020) adotou-se a narrativa como forma de recolha de dados, seguindo-se a mesma indicação aos alunos, alterando-se o ponto que se referia, na fase um, às expectativas sobre a UC, solicitando-se agora a opinião sobre o cumprimento das expectativas e como decorreu a UC. Assim, os alunos foram convidados a escrever uma narrativa onde abordassem os seguintes pontos:

1. Conhecimento sobre a MQ;

2. Comparação com a metodologia quantitativa;

3. Importância da MQ;

4. Importância da MQ na Psicologia;

5. Comparação com as expectativas iniciais da UC;

6. Como decorreu esta UC;

7. Importância da UC na formação do $2 . .0$ ciclo em PE; e

8. Outro(s) aspeto(s) que queira referir.

\subsection{Procedimentos}

Na última aula do semestre da UC de MI II, após a realização de 28 aulas (TeóricoPráticas e Seminário, tendo, cerca de dois terços delas, sido lecionadas, excecionalmente, em regime não presencial, devido à situação pandémica por COVID19), os alunos foram convidados à realização, mediante consentimento informado e participação voluntária, de uma narrativa, à semelhança da realizada na primeira aula, referindo se também autorizavam que fosse utilizada para fins de investigação. Como a aula foi lecionada em regime não presencial, através da plataforma Colibri/Zoom, os alunos presentes na mesma $(n=11)$ aceitaram participar e responder ao solicitado, via online também. A instrução da narrativa foi apresentada com recurso ao Microsoft Forms, facultando-se o link de acesso aos alunos, que responderam individualmente.

As narrativas foram recolhidas num ficheiro excel e copiadas verbatim para um ficheiro word, seguindo-se uma leitura integral e análise de conteúdo de acordo com Bardin (2008):

a) pré-análise, procedendo-se à organização do material, ou seja, a coleta e arquivo das narrativas, e atribuição de um código a cada participante;

b) exploração de materiais, ou seja, leitura integral das narrativas e tomada de decisão sobre a forma de análise das mesmas; $e$

c) análise, inferência e interpretação dos resultados, ou seja, análise e discussão dos dados recolhidos nas narrativas.

O processo de análise de conteúdo e de codificação decorreu em dois momentos. 
No primeiro, adotou-se uma lógica dedutiva, definindo-se a priori sete categorias de análise coincidentes com os pontos sugeridos para organização das narrativas (referidos atrás), pois a leitura iterativa prévia permitiu constatar que os alunos, de forma geral, seguiram esses pontos, sem referência a outros aspetos (ponto 8).

As autoras do estudo codificaram individualmente as narrativas, procedendo posteriormente à comparação e discussão da categorização efetuada até alcançarem acordo.

Num segundo momento, na sequência do processo anterior, e semelhante ao adotado em trabalho prévio (Antunes \& Araújo, 2020), procedeu-se a uma nova análise dos dados, numa lógica dedutiva e indutiva. Dedutiva porque se decidiu agrupar alguns Tópicos (1 e 2; e, 5 e 6), dada a aproximação nas narrativas, decidindo-se também a definição das categorias e subcategorias adotada em Antunes e Araújo (2020), a qual havia sido construída a partir das assunções filosóficas de Creswell (2007) e da proposta de Merriam (1998). Indutiva porque se decidiu abrir espaço à emergência de novas categorias ou subcategorias. Assim, as narrativas foram categorizadas para os seguintes tópicos:

(1) Caracterização da $M Q$;

(2) Importância da MQ;

(3) Importância da MQ na Psicologia;

(4) Experiência da UC; e

(5) Importância da UC no 2.ำ ciclo em PE.

As autoras voltaram a codificar individualmente as narrativas, procedendo-se posteriormente à comparação e discussão da categorização efetuada, até se alcançar acordo.

As categorias e subcategorias resultantes para cada tópico são apresentadas na secção dos resultados, sendo acompanhadas de excertos ilustrativos das narrativas, mantendose 0 anonimato dos alunos ao assinalar-se o excerto com a letra $A$ (indicação de aluno) seguida de um número (numeração de 1 a 11 atribuída a cada participante).

\section{Resultados}

Os dados são apresentados em função dos cinco tópicos definidos a priori: Caracterização da $\mathrm{MQ}$; Importância da $\mathrm{MQ}$; Importância da $\mathrm{MQ}$ na Psicologia; Experiência da UC; e Importância da UC no 2.ํㅜ ciclo em PE.

\subsection{Caracterização da MQ}

Neste tópico, foram identificadas sete categorias (ver Tabela 1). Destas, as categorias mais representadas foram o Propósito da investigação (três subcategorias) e Pressuposto metodológico (cinco subcategorias). As subcategorias mais frequentes estão associadas às categorias Propósito da investigação (Descrever/compreender, e Explorar fenómenos) e Dimensão do fenómeno (Idiográfica).

Tabela 1. Categorias e subcategorias para o tópico Caracterização da MQ.

\begin{tabular}{lll}
\hline \multicolumn{1}{c}{ Categoria } & \multicolumn{1}{c}{$\begin{array}{c}\text { Subcategoria } \\
\text { (frequência) }\end{array}$} \\
\hline $\begin{array}{l}\text { Paradigma/ visão } \\
\text { do mundo }\end{array}$ & Construtivismo (A5, A11) & $\begin{array}{l}\text { "Esta metodologia tem por base o } \\
\text { paradigma construtivista (...)" (A5) }\end{array}$ \\
& Abordagens (A7, A8) & "Esta metodologia tem diversos \\
& & $\begin{array}{l}\text { paradigmas associados, } \\
\text { nomeadamente a Grounded Theory, }\end{array}$
\end{tabular}




\begin{tabular}{|c|c|c|}
\hline Categoria & $\begin{array}{l}\text { Subcategoria } \\
\text { (frequência) }\end{array}$ & Extratos das narrativas \\
\hline & & $\begin{array}{l}\text { a fenomenologia, o estudo de caso, a } \\
\text { etnografia e a biografia." (A8) }\end{array}$ \\
\hline \multirow[t]{3}{*}{$\begin{array}{l}\text { Propósito da } \\
\text { investigação }\end{array}$} & $\begin{array}{l}\text { Descrever/compreender (A2, } \\
\text { A3, A4, A5, A6, A7, A8, A10, } \\
\text { A11) }\end{array}$ & $\begin{array}{l}\text { "(...) tem como principal intuito a } \\
\text { compreensão dos significados que os } \\
\text { sujeitos atribuem a um determinado } \\
\text { fenónemo de um determinado } \\
\text { contexto." (A2) }\end{array}$ \\
\hline & $\begin{array}{l}\text { Explorar fenómenos (A4, A5, } \\
\text { A6, A7, A8, A11) }\end{array}$ & $\begin{array}{l}\text { "(...) é um meio para explorar e } \\
\text { compreender o significado que os } \\
\text { indivíduos ou grupos atribuem a um } \\
\text { determinado problema ou fenómeno." } \\
\text { (A4) }\end{array}$ \\
\hline & Interpretar (A1, A2, A10) & $\begin{array}{l}\text { "A investigação qualitativa realiza os } \\
\text { estudos nos seus ambientes } \\
\text { naturais, procurando uma } \\
\text { interpretação." (A10) }\end{array}$ \\
\hline $\begin{array}{l}\text { Dimensão do } \\
\text { fenómeno }\end{array}$ & $\begin{array}{l}\text { Idiográfica (A2, A4, A5, A6, } \\
\text { A8, A11) }\end{array}$ & $\begin{array}{l}\text { "(...) preocupa-se em compreender } \\
\text { melhor os comportamentos dos } \\
\text { sujeitos, (...) dando mais atenção à } \\
\text { individualidade." (A6) }\end{array}$ \\
\hline $\begin{array}{l}\text { Pressuposto } \\
\text { ontológico }\end{array}$ & $\begin{array}{l}\text { Subjetividade (A1, A6, A7, } \\
\text { A10) }\end{array}$ & $\begin{array}{l}\text { “(..) a subjetividade da metodologia } \\
\text { qualitativa, (...) é algo que realmente } \\
\text { me cativou muito este semestre." } \\
\text { (A1) }\end{array}$ \\
\hline \multirow[t]{2}{*}{$\begin{array}{l}\text { Pressuposto } \\
\text { epistemológico }\end{array}$} & $\begin{array}{l}\text { Contextual (A2, A4, A5, A6, } \\
\text { A10) }\end{array}$ & $\begin{array}{l}\text { "Ao contrário da metodologia } \\
\text { quantitativa esta é mais próxima do } \\
\text { indivíduo, sendo o seu contexto } \\
\text { natural alvo de estudo" (A4) }\end{array}$ \\
\hline & $\begin{array}{l}\text { Proximidade do investigador } \\
(A 1, A 2,)\end{array}$ & $\begin{array}{l}\text { "Na qualitativa o principal } \\
\text { instrumento é mesmo o investigador } \\
\text { (...), e exige uma enorme } \\
\text { capacidade de atenção a tudo o que } \\
\text { acontece assim como escuta ativa. } \\
\text { (A2) }\end{array}$ \\
\hline $\begin{array}{l}\text { Pressuposto } \\
\text { axiológico }\end{array}$ & Assunção de valores (A10) & $\begin{array}{l}\text { “(..) apresenta várias realidades } \\
\text { subjetivas, o investigador reconhece } \\
\text { os seus valores }(\ldots) \text { " }\end{array}$ \\
\hline \multirow[t]{5}{*}{$\begin{array}{l}\text { Pressuposto } \\
\text { metodológico }\end{array}$} & $\begin{array}{l}\text { Recolha de dados (A3, A5, } \\
A 6, A 8)\end{array}$ & $\begin{array}{l}\text { “(..) recorre a entrevistas } \\
\text { semiestruturadas e narrativas, } \\
\text { maioritariamente, para a recolha dos } \\
\text { dados.” (A3) }\end{array}$ \\
\hline & Participantes (A6, A10, A11) & $\begin{array}{l}\text { “(..) a amostra é constituída por } \\
\text { poucos participantes" (A10) }\end{array}$ \\
\hline & Lógica indutiva (A11) & $\begin{array}{l}\text { “(...) é utilizada em fases iniciais dos } \\
\text { estudos acerca de alguma realidade, } \\
\text { com o intuito de explorar e de } \\
\text { fornecer explicações, daí ser } \\
\text { utilizado um raciocínio } \\
\text { tendencialmente indutivo.” }\end{array}$ \\
\hline & Resultados (A5, A6) & $\begin{array}{l}\text { "(...) sendo por isto os produtos da } \\
\text { investigação considerados } \\
\text { processos complexos, que exigem a } \\
\text { reflexão por parte do investigador." } \\
\text { (A5) }\end{array}$ \\
\hline & $\begin{array}{l}\text { Análise de dados (A5, A8, } \\
\text { A11) }\end{array}$ & $\begin{array}{l}\text { “(..) estes podem ser analisados } \\
\text { através de análise de conteúdo, de } \\
\text { análise documental, e outros.” (A8) }\end{array}$ \\
\hline
\end{tabular}




\subsection{Importância da MQ}

Relativamente ao tópico Importância da $\mathrm{MQ}$, apesar de ter sido possível identificar quatro categorias e cinco subcategorias, verifica-se a sua presença menos visível nas narrativas dos alunos (ver Tabela 2).

Tabela 2. Categorias e subcategorias para o tópico Importância da MQ.

\begin{tabular}{|c|c|c|}
\hline Categoria & $\begin{array}{l}\text { Subcategoria } \\
\text { (frequência) }\end{array}$ & $\begin{array}{l}\text { Extratos das } \\
\text { narrativas }\end{array}$ \\
\hline \multirow[t]{2}{*}{$\begin{array}{l}\text { Propósito da } \\
\text { investigação }\end{array}$} & $\begin{array}{l}\text { Descrever/compreender (A2, } \\
\text { A3, A8) }\end{array}$ & $\begin{array}{l}\text { "(...) não se deixa ficar apenas } \\
\text { por aquilo que os números } \\
\text { fornecem procura ir mais além, } \\
\text { compreendendo a realidade." (A2) }\end{array}$ \\
\hline & $\begin{array}{l}\text { Contributo à ciência (A1, A6, } \\
\text { A7) }\end{array}$ & $\begin{array}{l}\text { "Esta metodologia revela-se de } \\
\text { extrema importância, (...) } \\
\text { tornando-se uma mais valia para } \\
\text { a comunidade científica" (A6) }\end{array}$ \\
\hline $\begin{array}{l}\text { Dimensão do } \\
\text { fenómeno }\end{array}$ & Idiográfica (A6, A7, A8) & $\begin{array}{l}\text { "(..) acaba por enriquecer a } \\
\text { ciência com uma visão diferente } \\
\text { de um fenómeno em particular." } \\
\text { (A7) }\end{array}$ \\
\hline $\begin{array}{l}\text { Pressuposto } \\
\text { epistemológico }\end{array}$ & $\begin{array}{l}\text { Proximidade do investigador } \\
\text { (A3, A6, A8) }\end{array}$ & $\begin{array}{l}\text { "(...) permite uma maior } \\
\text { aproximação com o sujeito, de } \\
\text { modo a compreender a perspetiva } \\
\text { em relação à questão abordada." } \\
\text { (A8) }\end{array}$ \\
\hline $\begin{array}{l}\text { Pressuposto } \\
\text { metodológico }\end{array}$ & $\begin{array}{l}\text { Processo/Procedimento } \\
\text { investigativo (A7) }\end{array}$ & $\begin{array}{l}\text { "(...) permite estudar o fenómeno } \\
\text { de maneiras diferentes da } \\
\text { metodologia quantitativa, }(\ldots) \text {, usa } \\
\text { técnicas diferentes }(\ldots) \text { " }\end{array}$ \\
\hline
\end{tabular}

\subsection{Importância da MQ na Psicologia}

No que respeita ao tópico Importância da $M Q$ na Psicologia, duas categorias foram identificadas, desdobrando-se a primeira em três subcategorias, e sendo identificada uma única subcategoria na segunda (ver Tabela 3). À semelhança do verificado relativamente ao tópico 1 , as subcategorias mais representadas associam-se ao Propósito da investigação (Descrever/compreender) e à Dimensão do fenómeno (Idiográfica).

Tabela 3. Categorias e subcategorias para o tópico Importância da MQ na Psicologia.

\begin{tabular}{lll}
\hline Categoria & \multicolumn{1}{c}{$\begin{array}{c}\text { Subcategoria } \\
\text { (frequência) }\end{array}$} & $\begin{array}{c}\text { Extratos das } \\
\text { narrativas }\end{array}$ \\
\hline $\begin{array}{l}\text { Propósito da } \\
\text { investigação }\end{array}$ & Contributo à ciência (A3) & $\begin{array}{l}\text { "Na psicologia, esta revela-se } \\
\text { igualmente importante porque } \\
\text { possibilita originar conhecimento } \\
\text { científico sobre diversos aspetos } \\
\text { dos indivíduos ou de fenómenos } \\
\text { de interesse." }\end{array}$ \\
& $\begin{array}{l}\text { "Esta metodologia é relevante } \\
\text { Descrever/compreender (A2, }\end{array}$ & $\begin{array}{l}\text { para a psicologia, uma vez que } \\
\text { possibilita a compreensão de } \\
\text { determinados fenómenos, que }\end{array}$ \\
& não são possíveis de forma tão \\
& profunda através das outras \\
& metodologias da investigação." \\
& (A5) \\
& "Na psicologia, esta torna-se \\
& importante na medida em que
\end{tabular}




\begin{tabular}{|c|c|c|}
\hline Categoria & $\begin{array}{l}\text { Subcategoria } \\
\text { (frequência) }\end{array}$ & $\begin{array}{l}\text { Extratos das } \\
\text { narrativas }\end{array}$ \\
\hline & & $\begin{array}{l}\text { comportamento humano e esta } \\
\text { fornece uma (...) interpretação } \\
(\ldots) \text { dos mesmos." (A2) }\end{array}$ \\
\hline $\begin{array}{l}\text { Dimensão do } \\
\text { fenómeno }\end{array}$ & $\begin{array}{l}\text { Idiográfica (A1, A4, A5, A8, } \\
\text { A9) }\end{array}$ & $\begin{array}{l}\text { "Na psicologia, esta metodologia } \\
\text { é muito importante, uma vez que } \\
\text { permite uma interpretação da } \\
\text { vivência e significados atribuídos } \\
\text { às experiências do sujeito." (A8) }\end{array}$ \\
\hline
\end{tabular}

\subsection{Experiência da UC}

No que concerne o tópico Experiência da UC, verifica-se a identificação de três categorias nas narrativas dos alunos (ver Tabela 4). Destaca-se, pela sua representatividade no discurso destes, a categoria Processo ensino-aprendizagem e, nesta, de forma mais proeminente, as subcategorias Aprendizagem de conhecimentos e competências e Práticas pedagógicas. Registe-se, ainda, em mais de metade das narrativas analisadas, a referência ao Cumprimento de expectativas acerca da UC, alocada à categoria Aspetos motivacionais.

Tabela 4. Categorias e subcategorias para o tópico Experiência da UC.

\begin{tabular}{ll}
\hline \multicolumn{1}{c}{ Categoria } & \multicolumn{1}{c}{$\begin{array}{c}\text { Subcategoria } \\
\text { (frequência) }\end{array}$} \\
\hline $\begin{array}{l}\text { Aspetos } \\
\text { motivacionais }\end{array}$ & \\
& Promoção do interesse (A3) \\
(A1, A2, A5, A6, A7, A8) & \\
Processo ensino- & \\
aprendizagem & Aprendizagem de \\
& conhecimentos e \\
& competências (A1, A2, A3, \\
& A4, A5, A6, A7, A9, A10, A11) \\
& Práticas pedagógicas (A2, \\
& A3, A6, A8, A10, A11)
\end{tabular}

Apreciação global positiva (A4, A7, A8, A9)

Desmistificação de crenças (A1, A2, A7)

Apreciação das adequações à pandemia (A1, A7, A9, A10)
Extratos das narrativas

\section{"(...) esta disciplina promoveu-m \\ (...) interesse pela metodologia qualitativa como forma de investigação"}

"(...) aquilo que aprendi e a consciência que fui adquirindo acerca deste tipo de metodologia foi ao encontro das expectativas que tinha no início do ano letivo." (A6)

“(...) permitiu-me adquirir uma visão mais complexa do que realmente a investigação qualitativa implica." (A2)

"O trabalho de análise documental permitiu compreender melhor como analisar documentos, retirar as ideias principais, além de uma capacidade de investigação e busca de informação mais criteriosa." (A11)

"A UC correu bem e deu-nos uma visão geral do que é esta abordagem" (A4)

"Após este primeiro contacto com a metodologia qualitativa, considero que realmente todas as crenças de que esta é mais "fácil" ou menos científica que a metodologia quantitativa são erradas." (A1)

"Este modelo virtual não facilita a comunicação (por diversas razões), mas os obstáculos foram ultrapassados com sucesso e as aulas decorreram normalmente." (A9) 


\begin{tabular}{|c|c|c|}
\hline Categoria & $\begin{array}{l}\text { Subcategoria } \\
\text { (frequência) }\end{array}$ & $\begin{array}{l}\text { Extratos das } \\
\text { narrativas }\end{array}$ \\
\hline \multirow[t]{2}{*}{$\begin{array}{l}\text { Transferência da } \\
\text { aprendizagem }\end{array}$} & $\begin{array}{l}\text { Aplicação no percurso } \\
\text { académico (A6) }\end{array}$ & $\begin{array}{l}\text { "Sinto também que esta UC veio } \\
\text { acrescentar muita informação que } \\
\text { me será útil no restante percurso } \\
\text { académico" }\end{array}$ \\
\hline & $\begin{array}{l}\text { Aplicação em trabalhos } \\
\text { futuros }(A 3, A 4, A 6)\end{array}$ & $\begin{array}{l}\text { “(...) deu-nos uma visão geral (...) } \\
\text { de como podem ser tratados e } \\
\text { analisados os dados para depois } \\
\text { produzir um artigo científico." (A4) }\end{array}$ \\
\hline
\end{tabular}

\subsection{Importância da UC no 2.ำ ciclo em PE}

Neste tópico emergiram três categorias: Aspetos valorativos, Processo de ensinoaprendizagem e Transferência da Aprendizagem (ver Tabela 5). Relativamente à primeira, é patente numa parte significativa de alunos uma perceção da importância da UC, sendo que três alunos recomendam um contacto mais precoce com a IQ, designadamente na licenciatura. Além destas, é de notar que, à exceção da subcategoria Aprendizagem de conhecimentos e competências, as quarto subcategorias identificadas têm uma presença residual nas narrativas.

Tabela 5. Categorias e subcategorias para o tópico Importância da UC no 2.ํ ciclo em PE.

\begin{tabular}{|c|c|c|}
\hline Categoria & $\begin{array}{l}\text { Subcategoria } \\
\text { (frequência) }\end{array}$ & $\begin{array}{l}\text { Extratos das } \\
\text { narrativas }\end{array}$ \\
\hline \multirow[t]{2}{*}{ Aspetos valorativos } & $\begin{array}{l}\text { Perceção de } \\
\text { importância/mais valia (A1, } \\
A 2, A 3, A 5, A 6, A 7, A 8)\end{array}$ & $\begin{array}{l}\text { "Esta metodologia é importante na } \\
\text { formação do Psicólogo, porque dá } \\
\text { uma visão mais abrangente sobre } \\
\text { como a ciência é realizada" (A7) }\end{array}$ \\
\hline & $\begin{array}{l}\text { Recomendação da iniciação } \\
\text { na licenciatura }(A 1, A 3, A 9)\end{array}$ & $\begin{array}{l}\text { "(...) esta UC }(\ldots) \text { deveria ser } \\
\text { mais explorada ao longo da nossa } \\
\text { formação académica, } \\
\text { nomeadamente na licenciatura." } \\
\text { (A3) }\end{array}$ \\
\hline \multirow[t]{3}{*}{$\begin{array}{l}\text { Processo de } \\
\text { ensino- } \\
\text { aprendizagem }\end{array}$} & $\begin{array}{l}\text { Aprendizagem de } \\
\text { conhecimentos e } \\
\text { competências (A2, A5, A9, } \\
\text { A10) }\end{array}$ & $\begin{array}{l}\text { "(...) compreendo atualmente que } \\
\text { se trata igualmente de uma } \\
\text { investigação científica, mas que } \\
\text { visa chegar a um conhecimento } \\
\text { mais profundo e com mais } \\
\text { significado face às vivências do } \\
\text { sujeito e dos fenómenos que } \\
\text { analisa." (A5) }\end{array}$ \\
\hline & Prática pedagógicas (A2) & $\begin{array}{l}\text { "Ainda gostaria de referir que os } \\
\text { trabalhos realizados nesta UC } \\
\text { foram de extrema importância } \\
(\ldots) \text { ". }\end{array}$ \\
\hline & $\begin{array}{l}\text { Desmistificação de crenças } \\
\text { (A5) }\end{array}$ & $\begin{array}{l}\text { "(...) é uma mais valia esta UC, } \\
\text { pois contribui também para a } \\
\text { desconstrução de crenças, que } \\
\text { muitas das vezes, estão } \\
\text { enraiadas [sic], de que esta } \\
\text { metodologia não é tão científica } \\
\text { com as outras." }\end{array}$ \\
\hline \multirow[t]{2}{*}{$\begin{array}{l}\text { Transferência da } \\
\text { aprendizagem }\end{array}$} & $\begin{array}{l}\text { Suporte à tomada de decisão } \\
(A 6, A 7)\end{array}$ & $\begin{array}{l}\text { "(...) é importante termos } \\
\text { conhecimento sobre os métodos } \\
\text { quantitativos e qualitativos para } \\
\text { podermos escolher a abordagem } \\
\text { mais correta para realizarmos } \\
\text { uma investigação." (A7) }\end{array}$ \\
\hline & $\begin{array}{l}\text { Aplicação na dissertação (A1, } \\
\text { A3) }\end{array}$ & $\begin{array}{l}\text { “(..) sem dúvida que poder } \\
\text { estudá-la num ano em que iremos } \\
\text { realizar a tese ajuda imenso a }\end{array}$ \\
\hline
\end{tabular}




\begin{tabular}{lll}
\hline Categoria & $\begin{array}{c}\text { Subcategoria } \\
\text { (frequência) }\end{array}$ & \multicolumn{1}{c}{$\begin{array}{c}\text { Extratos das } \\
\text { narrativas }\end{array}$} \\
\hline & $\begin{array}{l}\text { poder considerar todas as nossas } \\
\text { hipóteses de investigação antes } \\
\text { de avançar." (A1) }\end{array}$ \\
\hline
\end{tabular}

\section{Discussão}

\subsection{Perceção sobre a MQ}

As perceções dos alunos sobre a $M Q$ evidenciam-se em três tópicos, que passamos a explicar:

a) A Caracterização da $\mathrm{MQ}$, verificando-se que os alunos revelam conhecimentos sobre aspetos importantes. Assiste-se, nesse sentido, à apreensão do Propósito da IQ, revelando a sua pertinência para explorar, descrever, compreender e interpretar a realidade em estudo. Além disso, reconhecem um Pressuposto metodológico diferenciado, em comparação à metodologia quantitativa, nomeadamente pela lógica indutiva, a forma de recolha de dados, o número reduzido de participantes, a análise de dados e os resultados. Acresce a consciencialização dos alunos sobre a Dimensão do fenómeno a estudar assente, tipicamente, numa perspetiva idiográfica.

b) A Importância da MQ, justificada pelos alunos através do Propósito da investigação, dado permitir descrever e compreender, dando contributo à ciência. Reconhecem ainda a importância da perspetiva idiográfica, destacando também, associado ao Pressuposto epistemológico, a proximidade do investigador.

c) A Importância da MQ na Psicologia, tópico onde referem aspetos relacionados com - Propósito da investigação, nomeadamente o permitir descrever, compreender, interpretar e contribuir para a ciência, referindo ainda a perspetiva idiográfica na Dimensão do fenómeno.

De uma forma geral, os alunos reconhecem a $M Q$ como forma de fazer ciência, valorizando o seu contributo na compreensão aprofundada do tema em estudo, estando em consonância com o seu reconhecimento recente (APA, 2020). Este facto parece promissor pois será de esperar que estes alunos se mostrem sensibilizados para realizar e consultar MQ no seu futuro académico e profissional e serem atores de mudança social (Gough \& Lyons, 2016), aparecendo a PE como um campo de atuação "privilegiado" para a MQ (Nolen, 2020).

Este grupo parece ter compreendido a essência da $M Q$ em termos de assunções filosóficas que pressupõem a sua realização (Creswell, 2007; Merriam, 1998).

\section{Apreciação da UC}

A apreciação dos alunos sobre a UC pode ser conhecida a partir de dois tópicos:

a) A Experiência da UC, verificando-se que os alunos destacam, em relação ao Processo ensino-aprendizagem, a aprendizagem de conhecimentos e competências e as práticas pedagógicas adotadas para a sua concretização. Manifestam ainda uma apreciação global positiva da UC, referindo as adequações efetuadas no contexto de ensino-aprendizagem devido à COVID-19, bem como o contributo da UC para a desmistificação de crenças que tinham sobre a $M Q$. No que se refere aos aspetos motivacionais, os alunos viram cumpridas as suas expectativas sobre a UC.

b) A Importância da UC no 2.ำ ciclo em PE revelou-se um tópico onde os alunos valorizaram a existência da UC no curso que frequentavam, de tal forma que alguns alunos sugerem o ensino de $\mathrm{MQ}$ mais cedo, ou seja, no 1. ciclo em Psicologia. 
Destaca-se, ainda, a referência ao Processo de ensino-aprendizagem, nomeadamente a Aprendizagem de conhecimentos e competências.

Este grupo de alunos parece ter tido uma experiência gratificante na UC de MI e, apesar da situação excecional vivenciada, devido à pandemia por COVID-19, permitiu o desenvolvimento de conhecimentos e competências sobre a MQ como verificado noutros trabalhos (Antunes, 2017).

De facto, o ensino e a aprendizagem de $\mathrm{MQ}$ são uma preocupação manifestada nalguns estudos (Antunes, 2017; Boström, 2019, Danquah, 2017, Wiggins et al., 2016). No caso concreto, parece-nos positiva a existência de uma UC obrigatória dedicada à $M Q$, integrada no plano curricular do curso. Não obstante, o desafio dos conteúdos programáticos e da lecionação mantêm-se (Gibson \& Sullivan, 2012), bem como a necessidade de atualização permanente do(s) docente(s), numa lógica de ser(em) mais "educados metodologicamente" (Nolen, 2020), explorando a pluralidade de opções metodológicas, nomeadamente na PE (Meyer e Schutz, 2020).

\section{Conclusões}

O presente trabalho permitiu conhecer as perceções de um grupo de alunos de mestrado em PE sobre a MQ e a sua opinião sobre uma UC de MI frequentada. Além disso, é um trabalho que traduz não só a importância da IQ, mas também alerta para a formação dos futuros investigadores, pois parece pertinente acautelar o ensino académico de IQ como parte integrante da estrutura curricular.

Este trabalho constitui a segunda fase de um trabalho anterior (Antunes \& Araújo, 2020) e duas considerações podem ser adiantadas. Uma, relativa à recolha de dados, ou seja, a apresentação da narrativa com tópicos orientadores poderá ter focado mais os alunos e inibido outras ideias, ainda que em trabalho anterior (Antunes \& Araújo, 2020), e neste, não pareça ter acontecido. Outra, referente à decisão tomada de analisar os dados recolhidos no segundo momento, sem comparação dos resultados das duas fases. Assim, num trabalho futuro poderá efetuar-se essa comparação, procurando perceber a evolução do grupo de alunos ao longo do semestre.

\section{Agradecimentos}

Este trabalho foi financiado por Fundos Nacionais através da FCT - Fundação para a Ciência e a Tecnologia no âmbito do projeto do CIEC (Centro de Investigação em Estudos da Criança da Universidade do Minho) com a referência UIDB/00317/2020 e do projeto do inED (Centro de Investigação e Inovação em Educação do Instituto Politécnico do Porto) com a referência UIDB/00317/2020.

\section{Referências}

Antunes, A. P. (2017). Formação académica em metodologia qualitativa: Prática pedagógica em Psicologia da Educação. Revista Lusófona de Educação, 36, 147-161. https://doi.org/10.24140/issn.1645-7250.rle36.10

Antunes, A. P., \& Araújo. S. B. (2020). Aprender metodologia qualitativa em Psicologia da Educação: Perceções e expectativas de alunos de mestrado. In S. O. Sá, F. Freitas, P. A. Castro, M. G. Sanmamed \& A. P. Costa (Eds.), New Trends in Qualitative Research (Vol. 2 , pp. 602-615). Ludomedia. doi: https://doi.org/10.36367/ntqr.2.2020.602-615

American Psychological Association (2020). Publication manual of the American Psychological Association. (7th ed.). https://doi.org/10.1037/0000165-000

Bardin, L. (2008). Análise de conteúdo. Edições 70. 
Vol. 7 | Investigação Qualitativa em Educação: Avanços e Desafios

Boström, P. K. (2019). In search of themes: Keys to teaching qualitative analysis in higher education. The Qualitative Report, 24(5), 1001-1011. https://nsuworks.nova.edu/tqr/vol24/iss5/5

Creswell, J. W. (2007). Qualitative inquiry and research design: Choosing among five approaches. (2nd ed.). SAGE Publications.

Danquah, A. N. (2017). Teaching qualitative research: A successful pilot of an innovative approach. Psychology Teaching Review, 23(2), 69-79. https://files.eric.ed.gov/fulltext/EJ1160262.pdf

Gibson, S., \& Sullivan, C. (2012). Teaching qualitative research methods in Psychology: An introduction to the special issue. Psychology Learning and Teaching, 11(1), 1-5. http://dx.doi.org/10.2304/plat.2012.11.1.1

Gough, B., \& Lyons, A. (2016). The future of qualitative research in Psychology: Accentuating the positive. Integr Psych Behav, 50, 234-243. https://doi.org/10.1007/s12124-015-9320-8

Meyer, D. K., \& Schutz, P. A. (2020). Why talk about qualitative and mixed methods in educational psychology? Introduction to special issue. Educational Psychologist, 55(4), 193-196. https://doi.org/10.1080/00461520.2020.1796671

Merriam, S. B. (1998). Qualitative research anda case study applications in education. Jossey-Bass Publishers.

Murray, M. (2019). Some thoughts on qualitative research in psychology in Europe. Qualitative Research in Psychology, 16(3), 508-512. https://doi.org/10.1080/14780887.2019.1605279

Nolen, S. B. (2020). Challenging research norms in educational psychology. Educational Psychologist, 55(4), 267-272. https://doi.org/10.1080/00461520.2020.1810043

Wiggins, S., Gordon-Finlayson, A., Becker, S., \& Sullivan, C. (2016), Qualitative undergraduate project supervision in psychology: Current practices and support needs of supervisors across North East England and Scotland. Qualitative Research in Psychology, 13(1), 1-19. https://doi.org/10.1080/14780887.2015.1075641 